This manuscript has been accepted for publication in The Lancet Group. The manuscript will undergo copyediting, typesetting, and review of the resulting proof before it is published in its final form. Please note that during the production process errors may be discovered which could affect the content, and all disclaimers that apply to the journal apply to this manuscript. A definitive version was subsequently published in The Lancet, [VOL 387, ISSUE 10015, (16 January 2016)] DOI: 10.1016/S01406736(15)00553-X.

\title{
Comment
}

\section{Trends in cause-specific mortality in Chinese provinces}

Authors: James Milner (james.milner@Ishtm.ac.uk), Paul Wilkinson (paul.wilkinson@Ishtm.ac.uk)

Affiliation: London School of Hygiene \& Tropical Medicine

Address: Department of Social \& Environmental Health Research, London School of Hygiene \& Tropical Medicine, 15-17 Tavistock Place, London, WC1H 9SH, UK

Corresponding author: Dr James Milner (james.milner@lshtm.ac.uk, +44 (0)20 7927 2510) 


\section{Main text}

China's extraordinary economic development has brought with it huge improvements in public health. Children born today in China are expected to live almost a decade longer on average than those born in $1990 .{ }^{1}$ The country now has more people aged 65 and over than any other country in the world, placing enormous pressures on its healthcare infrastructure. ${ }^{2}$ As average incomes have increased, lifestyles have changed, and access to healthcare has improved, the country has experienced a rapid transition away from infectious diseases and towards non-communicable disease. As a consequence, China today faces very different public health challenges from those of 25 years ago. Economic development, accompanied by rural-to-urban migration on an unprecedented scale, ${ }^{3}$ has also resulted in considerable social and environmental problems including a rapid rise in health inequalities ${ }^{4}$ and air pollution levels far in excess of recommended limits. ${ }^{5}$

In today's Lancet, Maigeng Zhou and colleagues report on trends in cause-specific mortality across provinces in China between 1990 and $2013 .{ }^{6}$ The authors collected available routine data for each province and performed analyses based on well-established methods developed for the Global Burden of Disease Study $2013 .{ }^{1}$ The work considered how patterns in 240 causes of deaths have changed over the period and examined differences in mortality in each of China's 33 province level administrative units.

The results demonstrate the enormous progress that has been made all across China. In 1990, lower respiratory infections and preterm birth were the leading causes of years of life lost (YLLs) in the majority of provinces. Since then, the national average age-standardised death rate has declined by almost a third and life expectancy has improved throughout the country. There have been substantial shifts in the major causes of mortality during that time, including remarkable reductions of beyond $90 \%$ in age-standardized death rates for infectious diseases, especially improvements in deaths from diarrhoeal disease and lower respiratory infections. Today, the leading causes of YLLS are stroke (also the leading cause in 27 provinces $^{7}$ ), ischemic heart disease (IHD), which is increasing 
in men but not in women (possibly due to high smoking rates in males), chronic obstructive pulmonary disease (COPD), and lung cancer. Not all causes of death have decreased, however, including deaths from various cancers, including prostate and pancreatic cancer and mesothelioma. Moreover, road traffic injuries now account for a greater proportion of YLLs in all mainland provinces, and there has also been a worrying lack of progress on HIV in many parts of the country.

The shift towards non-communicable disease has occurred in all provinces, but the major causes of death vary greatly. Zhou and colleagues suggest that China can in fact be divided into five distinct "nations" based on the epidemiological characteristics of each. In Shanghai, Tianjin, Zhejiang, Beijing, Hong Kong, and Macao, mortality rates are low and life expectancy high even relative to the standards of high income countries. In Jiangsu, Hainan, Guangdong, Fujian, Hubei, and Hunan, there is relatively high life expectancy due to low rates of IHD and stroke mortality, but high rates of cancer and COPD mortality. In a third group of mainly Northeastern provinces (Shandong, Jilin, Liaoning, Shanxi, Shaanxi, Henan, Anhui, Hebei, Inner Mongolia, Heilongjiang, and Ningxia), life expectancy is in the mid-range of all provinces, with high levels of mortality due to IHD, stroke, and cancers. In the fourth group of provinces mostly in Southwestern China (Jiangxi, Chongqing, Yunnan, Gansu, and Sichuan), life expectancy is lower than average and rates of COPD mortality are relatively high (although with relatively low IHD and stroke mortality). Finally, the group of Tibet, Xinjiang, Qinghai, Guangxi, and Guizhou have life expectancies which are more characteristic of low income countries.

Zhou and colleagues provide a fascinating snapshot of a global power at a critical stage in its development, and an invaluable detailed assessment of trends in the burden of mortality in China at the provincial level. As the authors highlight, the large gradients in causes of mortality across the country pose very different challenges to local health systems. This research will give healthcare professionals in individual provinces a better understanding of local health burdens, helping them to set their own priorities. 
China now faces the challenge of achieving further prosperity in a way which prioritises population health and environmental sustainability. There are encouraging recent signs. The government has just outlined plans for the expansion of the healthcare sector over the next five years ${ }^{8}$ and Premier Li Keqiang has recently "declared war" on environmental pollution. ${ }^{9}$ Even more promisingly, China has proposed plans for action to tackle climate change, pledging substantive cuts in greenhouse gas emissions and increases in low-carbon energy generation. ${ }^{10}$ If these and other commitments are kept, China has an opportunity to demonstrate that economic development does not have to be achieved at any cost.

\section{Contributors}

The text of this paper was drafted by JM and edited by PW.

\section{Conflicts of interest}

We declare no conflicts of interest.

\section{Role of the funding source}

Not applicable. 


\section{References}

1 GBD. Global, regional, and national incidence, prevalence, and years lived with disability for 301 acute and chronic diseases and injuries in 188 countries, 1990-2013: a systematic analysis for the Global Burden of Disease Study 2013. Lancet 2013; 385: 11771.

2 Zhao Y, Smith JP, Strauss J. Can China age healthily? Lancet 2014; 384: 723-4.

3 Gong P, Liang S, Carlton EJ, et al. Urbanisation and health in China. Lancet 2012; 379: $843-52$.

4 Baeten S, Van Ourti T, van Doorslaer E. Rising inequalities in income and health in China: who is left behind? J Health Econ 2013; 32: 1214-29.

5 Chen $\mathrm{R}$, Kan $\mathrm{H}$, Chen B, et al. Association of particulate air pollution with daily mortality: the China Air Pollution and Health Effects Study. Am J Epidemiol 2012; 175: 1173-81.

6 Zhou M, Wang H, Zhu J, et al. Cause-specific mortality for 238 causes in China, 19902013: a systematic subnational analysis for the Global Burden of Disease Study 2013. Lancet 2015.

7 Xu G, Ma M, Liu X, Hankey GJ. Is there a stroke belt in China and why? Stroke 2013; 44: 1775-83.

8 BMJ. China lays out bold plan to improve healthcare. BMJ 2015; 350: h1877.

9 Reuters. China to 'declare war' on pollution, premier says. 2014. http://www.reuters.com/article/2014/03/05/us-china-parliament-pollutionidUSBREA2405W20140305 [Accessed 14 July 2015]. BBC News. China climate change plan unveiled. 2015.

http://www.bbc.co.uk/news/science-environment-33317451 [Accessed 17 July 2015]. 